\title{
Relation between micro- and macro-diamonds: Myth, myopia or both?
}

\author{
Stephen E. Haggerty \\ Florida International University MIAMI, FL 33199, USA, haggerty@fiu.edu
}

\section{Introduction}

The origin of micro-diamonds $(<0.5 \mathrm{~mm})$ has been a topic of long standing debate and uncertainty. Once entirely of academic interest, the presence and determination of micro-diamonds has received increasing attention over the past two decades to the point that these barely visible diamonds are now center stage to kimberlite exploration and modern evaluation programs. The underlying assumption in this progression is that micro-diamonds are a measure of, and directly related to, the presence and abundance of macro-diamonds, thus providing an inexpensive method of potential grade determination. And as such, micros have become a requirement (an industry norm) to investment. Among several important questions are whether micros and macros shared a common C-source, and whether both experienced the same P-T-t conditions and origin in the mantle, which reduces fundamentally to: Did the two populations ever co-exist? The answers individually and collectively provide an assessment of the overall reliability of a micro to macro relationship. The relation of size vs abundance is ideally modelled as being uniformly log-normal (Rombouts, 1994, 1995), but in fact micros are linear, macros are quadratic, and the two are separated by a discontinuity (Chapman \& Boxer, 1984; Deaken \& Boxer, 1989), as illustrated in Fig. 1 (Lock \& Barton, 2007); the extrapolation of abundant micros to sizes of value cannot, therefore, be tacitly assumed (Coopersmith et al., 2002). The vast majority of kimberlites contain micro-diamonds but there are few studies relating these to macros, (drawn upon below from e.g. McCandless et al., 1994; Patterson \& Levinson, 1995; Johnson et al., 2012; Melton et al., 2013).

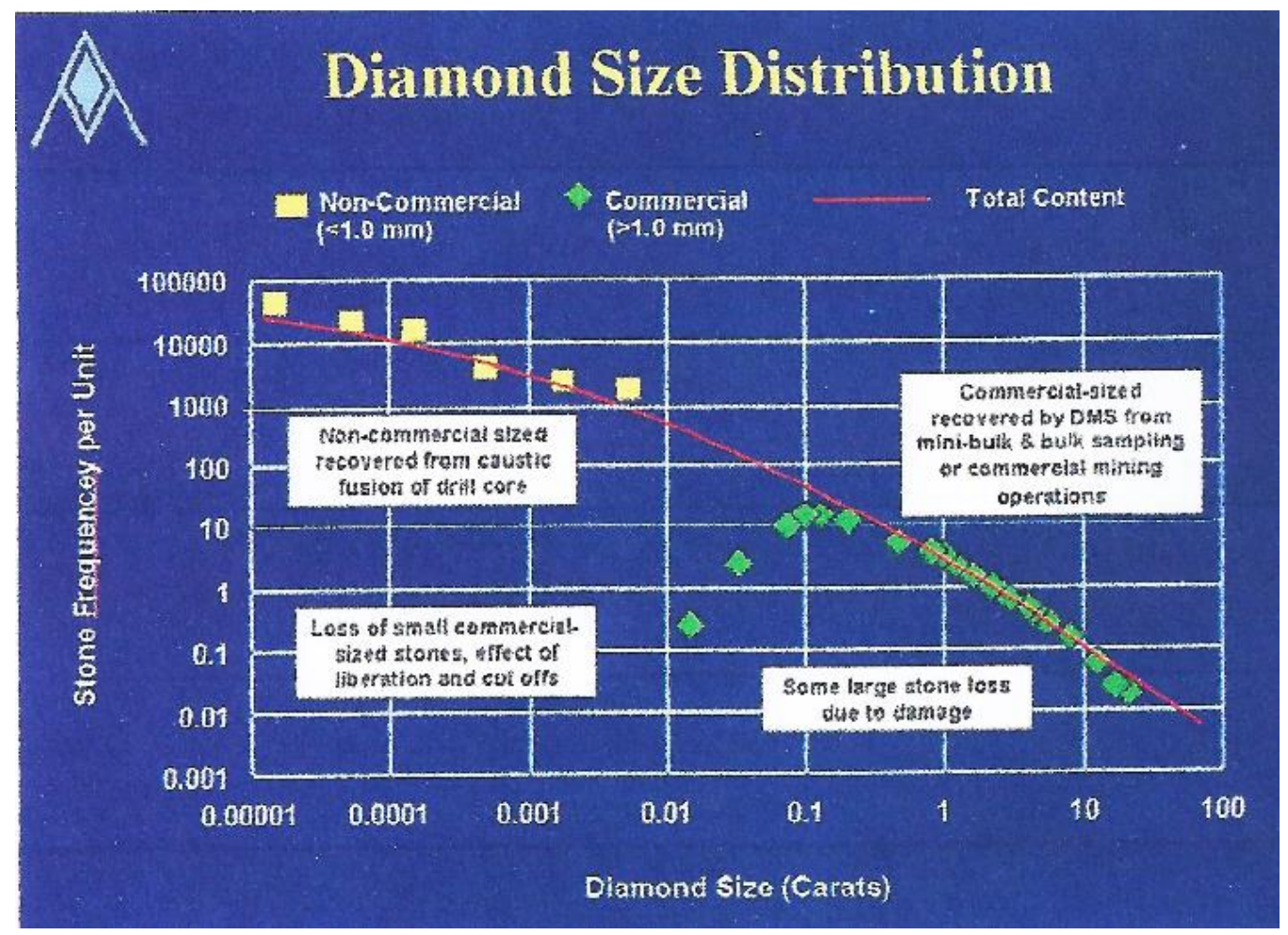

Fig. 1 Typical relation between micros (yellow squares) and macros (green diamonds). 


\section{Are Micros and Macros related?}

Micro-diamonds generally have the following features: typically octahedra and free of mineral inclusions, growth ornamentation, etch and corrosion features; and abundance is overwhelmingly greater than macros.

First order objections to this relationship are:

1. Given the lateral and vertical heterogeneities in the mantle, the inferred distribution of rock types in the subcontinental lithosphere, the transition zone and the lower mantle, it is reasonable to expect that the distribution of carbon is highly variable, and that the abundance of diamond and the population of sizes must be equally heterogeneous.

2. This heterogeneity must also apply to the mechanisms of nucleation, growth, and dissolution in which populations of micros and macros are assuredly variable rather than cohesive.

3. Sampling at depth and along the eruptive conduit is chaotic with assured mixing of rocks, both diamond and non-diamond bearing that lack discrimination in population sizes or in sampling efficiency; and if intrinsic relations once existed these were surly lost on explosive eruption.

4. This is manifest in the fact that all kimberlites are multiple intrusions with highly variable diamond contents between intrusions and within the same intrusive body. Hence, a strict correlation between micros and macros is highly unlikely.

5. Harzburgites and eclogites are the major hosts to diamonds, the latter being typically higher in diamond content and with significantly larger diamonds. Thus, if micros are intrinsically related to macros it follows that peridotitic suites ought to be deficient in micros. And because the diamond populations are mixed, the end result in the kimberlite must also be mixed. With diminished micros in one rock type and potentially large and abundant diamonds in another the relation between micros and macros must inevitably be incoherent.

6. Modelled ideally as oxidation of $\mathrm{CH}_{4}$ or reduction of $\mathrm{CO}_{2}$ the diamond yield should be equal, but macros and micros are unequal in size and abundance further implying that the two populations are genetically unrelated.

7. Micros are typically Type Ib octahedra or Type II, whereas macros are Type Ia octahedra commonly corroded to dodecahedra or tetrahexahedra. These differences clearly indicate that the two populations cannot have co-existed under the same P-T-t environments in the mantle.

8. C-isotopes and $\mathrm{H}$-contents are equivocal possibly because of mixed populations of micros and diamond fragments that are small but are not micros sensu stricto.

9. The broad-based continuum from micro- to macro-diamonds is separated by the "Chapman \& Boxer Discrepancy Zone." (Fig. 1), and ignores the ultra-ultra-fine population at one extreme that is never recovered analytically, and mega-stones at the other that are rarely encountered. Further complications are shown in the comprehensive treatment by Hutchinson (2012) in Fig. 2.

10. With a huge disparity in the surface to volume ratio, micros and macros cannot be of the same age, or have resided over the same period of time in an environment of constant $\mathrm{C}$, or in a setting affected by the same corrosive mantle fluids (Haggerty, 1986). In essence, if micros and macros are coeval then what inhibited growth of the former, and why is it that only the latter are affected by dissolution?

11. There is also a huge disparity in methodology: Micros are determined on $\sim 200 \mathrm{~kg}$ of kimberlite by acid dissolution or caustic fusion; Macros are concentrated from $20,000 \mathrm{~T}$ in bulk sampling programs by mechanical and X-ray means on crushed kimberlite + xenoliths + crustal enclaves. That there should be any relationship between the two diamond populations stretches credulity.

12. Having micros "protected in xenolith" from kimberlite attack (Robinson et al., 1989), or progressive release in the conduit are unlikely because it's slow corrosion not combustion. Moreover, the mantle is a massive body of $\mathrm{P}$ and $\mathrm{E}$ diamond-bearing host rocks hundreds of cubic $\mathrm{km}$ in extent---- not a mélange of disruptive xenoliths! 


\section{Genesis of Micros \& Macros}

Given the existence of lower mantle (bridgemanite) and TZ-diamonds (ringwoodite and majorite), young intrusive-age Type Ib micros are from $>660 \mathrm{~km}$ and permissively from plume-bearing D" carbon in proto-kimberlites; micro-diamonds formed from large numbers of nucleation centers in the upward

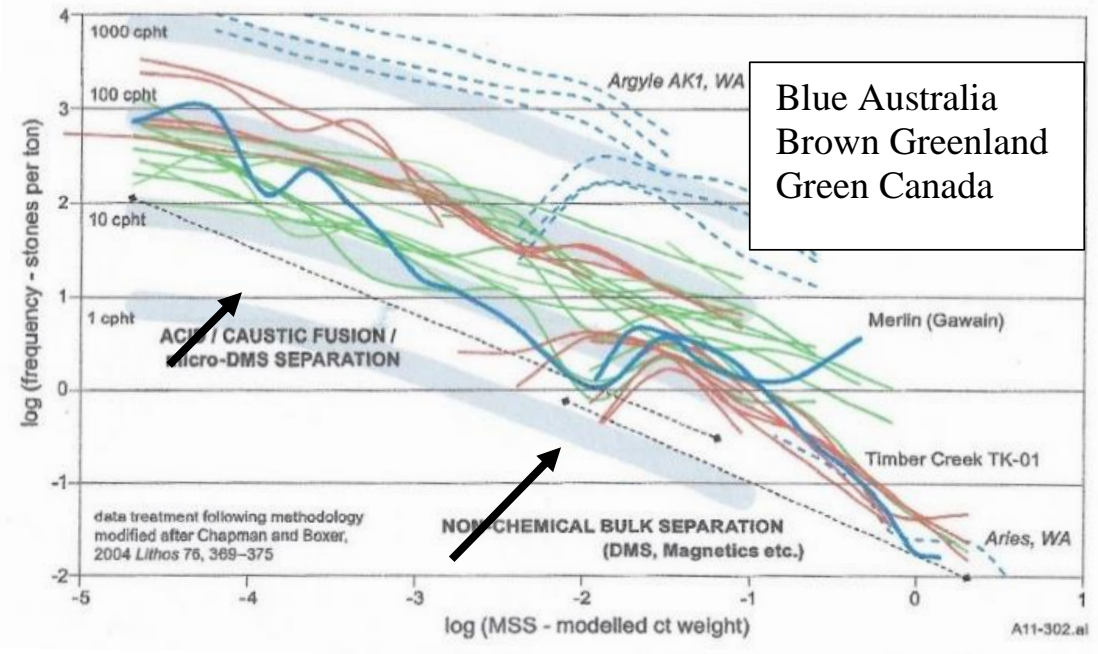

moving plume. By contrast, ancient Type Ia macros $(2.8-3.2 \mathrm{Ga})$ are from primordial mantle carbon, with crystallization by thermochemical cracking of fluid/gas species under variable $\mathrm{fO}_{2}$ from small numbers of diamond nucleation sites; slow and intermittent growth, dissolution by hyperactive metasomatic fluids, and with resident annealing over long periods of time under high P-T conditions.

Fig. 2. Log cpht vs log mean stone size.

\section{Conclusions}

Micros and macros are seemingly unrelated so any inferred relation is mythical and the widespread lognormal association, so common in nature (Lampert et al., 2001), is myopic (by definition: shortsighted, unimaginative, and unrealistic). Possible exceptions are: (i) diamonds are uniformly small; (ii) breakage is extensive; (iii) micros and fragments of macros are mixed; and (iv) if $\mathrm{C}$ from the partial solution of Type 1a macros becomes the source of $\mathrm{C}$ in Type $1 \mathrm{~b}$ micros, a continuum might be expected if both are retained in a single intrusive body-----a most unlikely scenario!

\section{References}

Chapman JG and Boxer GL (2004) Lithos 76, 369-375.

Coopersmith H, Pell J, Scott-Smith B (2002) Kimberlite Emplacement Workshop. Saskatoon. Unpaged. Deakin AS and Boxer GL (1989) Geol. Soc. Australia Spec. Paper 14, 1117-1122.

Haggerty, SE (1986) Nature 320, 34-38.

Hutchinson MT (2012) Proc. 10 ${ }^{\text {th }}$ IKC India 2, 257-280.

Johnson CN, Stachel T, Muehlenbachs K, Stern RA, Armstrong JP (2012) Lithos 148, 86-97.

Lampert E, Stahel WA Abbt M (2001) BioScience 51, 341-352.

Lock N and Barton E (2007) Geol. Soc. South Africa. Kimberley Symposium. Unpaged.

McCandless TE, Waldman MA, Gurney JJ (1994) Proc. $5^{\text {th }}$ IKC Brazil 2, 78-97.

Melton GL, Stachel T, Stern RA, Carlson J, Harris JW (2013) Lithos 110-119.

Pattison DRM, Levinson AA (1996) Applied Geochemistry 10, 725-738.

Robinson DN, et al. (1989) Geol. Soc. Australia Spec Pub. 14, 990-1000.

Rombouts L (1994) Proc. $5^{\text {th }}$ IKC, Brazil. 2, 203-214.

Rombouts L (1997) Russian Geology \& Geophysics. 38, 599-611. 